TEI

JOURNAL OF THE DURNAL OF TH

\section{Journal of the Text Encoding Initiative}

Issue 1 | June 2011

Selected Papers from the 2008 and 2009 TEI Conferences

\title{
Knowledge Representation and Digital Scholarly Editions in Theory and Practice
}

\section{Tanya Clement}

\section{(2) OpenEdition \\ Journals}

Electronic version

URL: http://journals.openedition.org/jtei/203

DOI: $10.4000 /$ jtei.203

ISSN: 2162-5603

Publisher

TEl Consortium

Electronic reference

Tanya Clement, « Knowledge Representation and Digital Scholarly Editions in Theory and Practice », Journal of the Text Encoding Initiative [Online], Issue 1 | June 2011, Online since 08 June 2011,

connection on 02 May 2019. URL : http://journals.openedition.org/jtei/203 ; DOI : 10.4000/jtei.203

This text was automatically generated on 2 May 2019.

TEI Consortium 2011 (Creative Commons Attribution-NoDerivs 3.0 Unported License) 


\title{
Knowledge Representation and Digital Scholarly Editions in Theory and Practice
}

\author{
Tanya Clement
}

\section{Introducing In Transition: Selected Poems by the Baroness Elsa von Freytag-Loringhoven}

1 In Transition: Selected Poems by the Baroness Elsa von Freytag-Loringhoven is a publicly available scholarly edition of twelve unpublished poems written by Freytag-Loringhoven between 1923 and 1927. Alongside extensive annotations and a critical introduction, this edition serves to provide access to a textual performance of her creative work in a digital environment. It is an interaction that is made possible by using the Text Encoding Initiative's (TEI) P5 Guidelines for critical apparatus including parallel segmentation and location-referenced encoding. The encoded text is rendered into an interactive web interface using XSLT, CSS, and JavaScript available through the Versioning Machine (VM). ${ }^{1}$ In this discussion, I show that a digital edition like In Transition is formed as much by the underlying theory of text as it is by its content and the particular application or form it takes. This discussion employs the language of knowledge representation in computation (through terms like domain, ontology, and logic) in order to situate this scholarly edition within two existing frameworks: theories of knowledge representation in computation and theories of scholarly textual editing. 


\section{Knowledge Representation and Digital Scholarly Editions in Theory}

2 John F. Sowa writes in his seminal book on computational foundations, that theories of knowledge representation are particularly useful "for anyone whose job is to analyze knowledge about the real world and map it to a computable form" (Sowa 2000, xi). Sowa's suggested approach to designing systems for digital knowledge representation is not dissimilar to the principles set forth in the Modern Language Association's (MLA) "Guidelines for Editors of Scholarly Editions" (2007). The MLA Guidelines recommend that an editor "choose what to attend to, what to represent, and how to represent it" according to "the editor's theory of text" or "a consistent principle that helps in making those decisions" (MLA 2007). An analogy can be made between these guidelines and Sowa's assertion about the application of knowledge representation: "Knowledge representation," he writes, "is the application of logic and ontology to the task of constructing computable models for some domain" (xii). Sowa's concept of logic or "pure form" maps to the MLA guidelines' consideration for how a text is represented in an edition; his use of ontology or "the content that is expressed in that form" maps to the MLA guideline's concern with what is attended to or represented in an edition; and Sowa's consideration for the domain maps to the MLA guidelines' notion of an edition's underlying theory of text (Sowa 2000, xiii). Further, the MLA guidelines consider a scholarly edition "a reliable text" by measuring its "accuracy, adequacy, appropriateness, consistency, and explicitness" against what editors define as the edition's form, content, and theory of text (MLA 2007). Similarly, Sowa notes that knowledge representation is unproductive if the logic and ontology which shape its application in a certain domain are unclear: "without logic, knowledge representation is vague, Sowa writes, "with no criteria for determining whether statements are redundant or contradictory," and "without ontology, the terms and symbols are ill-defined, confused, and confusing" (xii). Knowledge representation is the work of all editors. Moreover, the work that scholarly editors undertake in a digital environment must take into account, not only traditional textual scholarship, but theories in computation. It is thus useful to theorize the extent to which the production of knowledge in a digital edition is unique to this environment.

\subsection{The Domain and Theory of In Transition: Textual Performance}

In Transition reflects a theory of text I am calling textual performance. Textual performance theory is based on John Bryant's notion of fluid text theory in which social text theory is combined with the geneticist notion that a literary work is "equivalent to the processes of genesis that create it" (Bryant 2002, 71). What is productive about this theory for this discussion is the notion that a textual event is a "flow of energy" rather than a product or a "conceptual thing or actual set of things or even discrete events" (Bryant 2002, 61). Accordingly, a text in performance comprises multiple versions in manuscript and print, various notes and letters and comments of contemporaries or current readers, plus the element of performance, which entails time, space, and a collaborative audience. We can perceive these elements working together in the meaning-making event of a text if we consider a literary work to be a "phenomenon ... best conceived not as a produced work ( oeuvre) but as work itself (travaille), the power of people and culture to create a text" 
(Bryant 2002, 61). As well, considering the literary work as a phenomenon situated in space and time corresponds to the Baroness's notion of "lifeart," which reflects a concept of art that was germane to the Dadaist movement, one even Ezra Pound adopted as "an act of art" instead of "a work of art" (Gammel 2002, 14). In other words, as a Dadaist, the "act" of art was intricately tied with one's ability to provoke a response from fellow Dadaists and the bourgeois culture, which were the targets of most Dada performances. Because provocation was at the root of Dadaist art, the context in which Dada art is performed and the fact of a live, collaborative audience are essential to the art. Likewise, this concept of the "flow of energy" within fluid text theory is a useful way of thinking about how meaning is being produced when a reader interacts with an electronic edition of the Baroness's poetry.

The Baroness's particular perspective on creating art coheres to this sense of flow and the nature of creation in terms of historical time and place. First, the Baroness believed that for the artist, "art" is conceived in a wave of imagination that comes before its logic or form and that the medium then serves as a catalyst or a signpost within the creative act. In a letter to Djuna Barnes the Baroness refers to the overwhelming nature of being an artist and the productive and enabling forces of the logic or form of poetry. She writes to Barnes that her "rambling" way of "analytical speculation by emotional facts" is an "endless way -until now only to be mastered by rhythmical [sic] and symbolical force of poetry" in which "the logic is already the motive of the very start-and is contained in it and is the thing itself" (UMD 2.144). ${ }^{2}$ In another letter the Baroness notes, "I am all wave -first-arrangement-ability-comes later" since "the possibility of the structure grows your wings to "create"' (UMD 2.45). In other words, various poetic expressions may start from the same wave, but each medium's particular structure lends itself to a unique performance of that expression. This method is apparent in other poems by the Baroness such as "Orgasmic Toast," "Statements on Circumstanced Me" (also called "Purgatory Lilt" and "Hell's Wisdom"), and "Christ - Don Quixote - St. George," which have multiple versions written as prose in paragraphs and other versions structured into more traditional stanza-and-line formats.

Using different styles, genres, and forms was part of the Baroness's creative process. She writes in a note on a version of "Purgatory Lilt" she has included in a letter to Barnes that "This is not a poem but an essay-statement. Maybe-it were better not to print it in this cut form-perpendicular but in usual sentence line-horizontal?" (UMD 2.226-227) Hans Richter calls this process of revision more dream-like than fancy: "What is important is the poem-work, the way in which the latent content of the poem undergoes transformation according to concealed mechanisms," transformations "that work the way dream-work strategies operate-through condensation, displacement, and the submission of the whole of the text to secondary revision" $(1965,80)$. For these reasons, the Baroness's manuscripts often do not correspond to a sequence that manifests the teleological evolution of a poem. In some cases, the extant manuscripts show little evidence of a clear, creative evolutionary path within a text. Indeed, the Baroness's manuscripts often manifest experiments on a theme, making one version's relationship to another an example of alternative choices rather than a system of rough drafts leading to final versions. Richard Poirier claims that this is a modernist technique: "[m]odernist writers, to put it too simply, keep on with the writing of a text because in reading what they are writing they find only the provocation to alternatives" $(1992,113)$. A reading 
environment where the reader can experiment based on textual provocations reflects these Dadaist and modernist textual practices.

One aspect of textual performance theory I am exploring within In Transition concerns the social text network. The social text network these twelve texts always and already represent presupposes the notion of a constant circulation of networked social text systems. A social text network is entered much like one enters McGann's "editorial horizon": the entrance point is "the words that lie immediately before a reader on some page [which] provide one with the merest glimpse of that complex world we call a literary work and the meaning it produces" (Textual Condition 12). The network represented by In Transition is based primarily on issues of reception, materiality, and theme which engage and reflect the social nature of the text in the 1920s and now. This is to say two things: (1) that the concept of the network is not new with digital scholarly editions; and (2) that these networks in a digital edition foreground the situated 1920s history of these texts as well as the real-time, situated electronic reading environment.

7 Social networks are not new. Indeed, the notion of the network is used both by Bruno Latour and Jay David Bolter and Richard Grusin to ameliorate the polarities that exist in the current discourse between nature and technology and between "old" and "new" technologies. Notions of the "network" help to diminish the polarities within the overriding discourse. In We Have Never Been Modern (1993), Bruno Latour explores the notion that the hybridization of nature and culture in this age of new technologies has necessitated discourses of purification and denial; these discourses, he argues, seek to create an age of digital "revolution" that diminishes what has always been a cyborgian culture (48). "When we see them as networks," Latour writes, "Western innovations remain recognizable and important, but they no longer suffice as the stuff of saga, a vast saga of radical rupture, fatal destiny, irreversible good or bad fortune" $(1993,48)$. Bolter and Grusin explore our current, perceived digital utopia as the result of the "doublelogic" of "remeditation" (the "repurposing" of old technologies) in which "our culture wants both to multiply its media and to erase all traces of mediation" (Bolter and Grusin 1998, 5). In Transition is a remediation of social text networks, but it is also the enactment of new social text networks that is in constant circulation or "flow." The realtime audience participation required within the In Transition interface foregrounds the extent to which these social text networks underlie all textual performances or events.

\subsection{The Ontology and the Content: Social Text Networks}

This scenario, in which the making of meaning is a performance that relies on a constant state of shifting social networks corresponds to the edition's central theme of transition. These twelve texts are included as expressions created during a time of transition in the Baroness's life between 1923 and 1927 when she moved from New York to Berlin and finally to Paris, but the edition also serves to represent a moment of transition in the culture of little magazines and the technologies of conversation during this time period. This is a period which sees the little magazine change shape from a venue that engages more popular responses and conversations about literature and art-such as the one represented by the inclusion of the Baroness's poetry in The Little Review-to a venue which begins to address an audience more attuned to and engaged with literature and poetry as high art. Alan Golding associates the "point that modernism becomes Modernism" with the moment that the Baroness left New York to return to Germany in 
1923, a point that signals both a highly experimental phase of modernist writing and one in which conversation and dialog was freely flowing (Golding 76).

9 The social text networks represented by In Transition comprise three primary relationships within this context. The first relationship is based on the reception environment at transition magazine ${ }^{3}$ where the editors at first accepted and then rejected the Baroness's poems for their audience in the late nineteen-twenties. ${ }^{4}$ For instance, during the period between 1927 and 1929, three of the twelve poems included within In Transition ("Café Du Dome," "Xray," and "Ostentatious") were published in transition while five of the other poems-"Ancestry," "Christ-Don Quixote-St. George" (a subsection of "Contradictory Speculations"), "Cosmic Arithmetic," "Sermon On Life's Beggar Truth," and "A Dozen Cocktails Please"-were under consideration by the transition editors and ultimately rejected for future issues. ${ }^{5}$ Cary Nelson argues that this time period is one in which "a revolution in poetry seemed naturally to entail a commitment to social change [. ..] all the arts were in ferment and aesthetic innovations were politically inflected" (230). Much of this fermentation, innovation, and commitment to change was generated by the relationships between writers and editors. Indeed, the conversation at the root of modernism extended to the offices of the little magazines where writers read each other's work and discussed it both in person and in print. These eight poems share a relationship tied to the particular social text network engaged by the transition editors in the 1920s.

A second relationship represented by the textual network within this edition includes the material space that some of these poems share, a relationship that in some cases overlaps with the ties just mentioned. For instance, in some cases, draft versions of certain poems appear on the verso or in the margins of the manuscripts for draft versions of other poems. Versions of "Café Du Dome," "Ancestry," and "Sermon" appear on versions of "Ostentatious" while versions of "Orchard Farming," "Sermon," "Christ -Don Quixote St. George," and Ostentatious" appear on versions of "Xray." The material nature of these relationships is useful for considering the role that materiality plays in situating these poems in a particular time and place, both historically and in the present. That is, a reader could assume that two poems were produced in close succession because they share a manuscript leaf, but it is also true that the Baroness was quite poor and could have reused these sheets multiple times over a long span of time for economical reasons. Further, it is difficult to say if the proximity of one poem influenced how the Baroness wrote another. At the same time, in the current iteration of In Transition in which images of the manuscripts are used, the reader is exposed to multiple poetic events each time she opens a manuscript leaf that shows multiple poems. As a result, these material relationships play a role in both the text's perceived material history and the materiality of its current performance.

The third interconnected relationship embodied by the content within this edition is one that is determined by thematic ties between poems written during this time period. The remaining three poems "Purgatory Lilt/ Statements by Circumstanced Me," "Orgasmic Toast," "Matter Level Perspective" have thematic ties with a variety of the aforementioned texts. For instance, the interplay among historical, personal, scientific, and creative forces in "Hell's Wisdom" points to themes inspired by the Baroness's fellow Dadaists, but it is difficult to decipher the abstract logic that the arithmetic in a poem like "Hell's Wisdom" represents unless one also reads "Cosmic Arithmetic." The other poems share thematic ties as well, such as images of "radiance" in "Orgasmic Toast," "Sermon on Life's Beggar Truth," "Purgatory Lilt," and "Xray" or mathematic formulas in "Orgasmic 
toast," "Purgatory Lilt," and "Cosmic Arithmetic." More of these relationships are explored in the extensive introduction and annotations to the edition.

Reception, thematic, and materiality networks are also reflected in the relationships between words and forms of punctuation across different versions of the poems. For instance, in the poem "Sermon on Life's Beggar Truth" words are underlined in one version and then not emphasized at all; dashes and colons are deleted and replaced with periods or spaces or exclamation points (and vice versa); and all of these relationships occur in an order that seems to contradict a linear evolution of text. For instance, Figure 1 shows the relationship between the words "Menacing" and "Behold," which function as "heading" words for two prose stanzas. These words change in similar ways across multiple versions but not in a similar sequence. In versions one and two, "Menacing" and "Behold" remain consistent, underlined with a colon. In versions three through six, "Menacing" is not underlined but is separated from the following prose group by a space. In versions five and six it has a colon while in versions three and four, it has an exclamation point. "Behold" is always on its own line but the colon is deleted and replaced by an exclamation point in version five while versions three, four, and six maintain the colon and so on. The progression shows a network of relationships that hint at multiple performances or instantiations of the poems instead of a teleological process towards an end result. In contrast, there are other social text networks between versions that are linear. The poem "Xray," for example, which was published in transition (October 1927) has nine extant versions that show changes that we can map to the reception and materiality relationships between nodes. For example, the first three lines of the first stanza of the published version read:

Nature causes brass to oxidize

People to congest-

By dull-radiopenetrated soil ... .

In the first version in the interface, the first line is "Nature causes brass to oxidize," which changes to "Nature intends brass to oxidize" in version six. The second line in the first version is "Nature causes people to amass," which becomes in version six, "Nature intends people [sic] to amass"; this line evolves in version two to "Nature causes people to congest" and eventually becomes, in the published text, a truncated clause: "People to congest-." While the evolution of these lines are relatively easy to follow, the third line becomes something that seems entirely different if one merely looks at the last version in comparison to the first: "Because of latent ideal of brilliancy" becomes "By dullradiopenetrated soil" (see Figure 2). The Baroness's compulsive desire to create multiple versions of each work is reflected in the ontology or content across which particular words, punctuation marks, and symbols move and change. 
Figure 1: The words "Menacing" and "Behold" compared across versions of "Sermon on Life's Beggar Truth" in the Versioning Machine

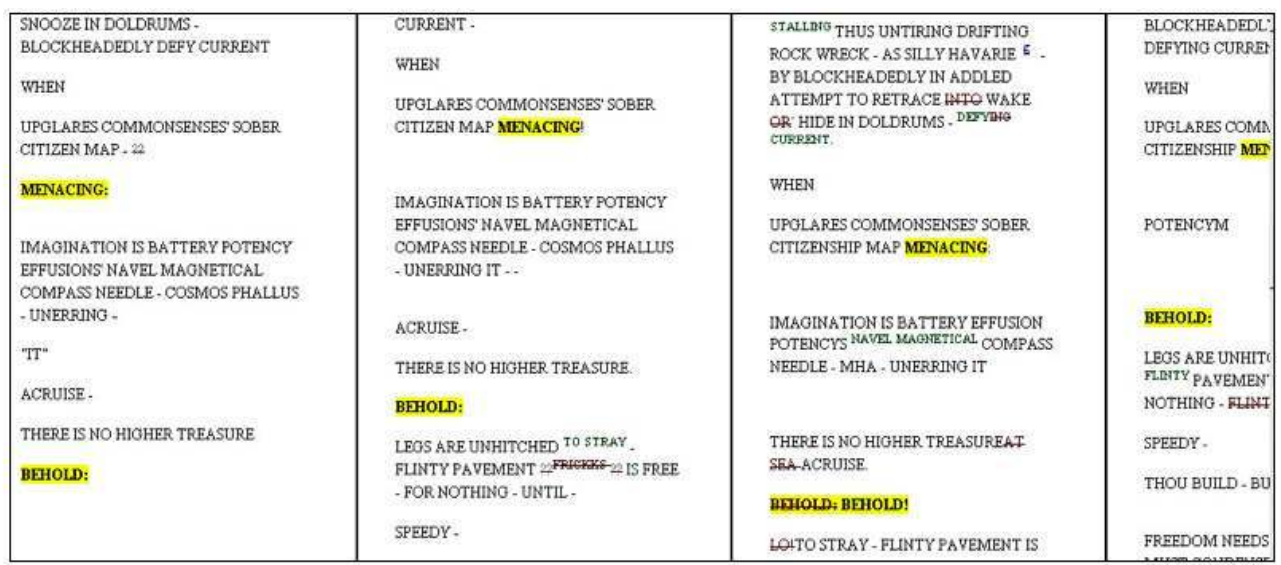

Figure 2: "Xray", versions one, eight, and the published 1927 text, in the Versioning Machine

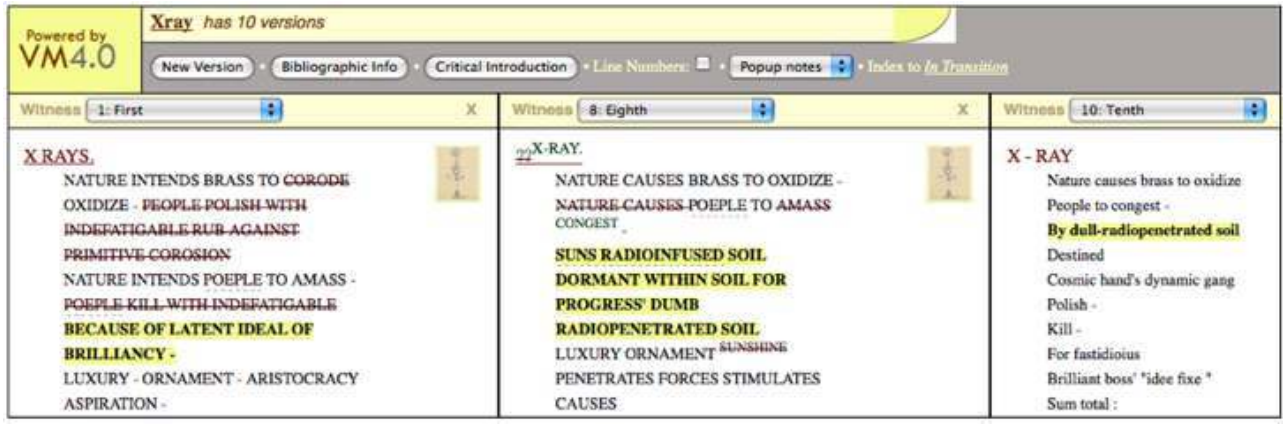

14 In short, all twelve poems participate by and through multiple and varied relationships based on reception, materiality, and theme within the textual network that was circulating between 1923 and 1927. In Transition stages a textual performance that sets these social text networks into play.

\subsection{Logic and Form: the TEl in the Versioning Machine}

Encoding a transcription of a printed or manuscript text is a method for creating a computable model of a text that can be instantiated or implemented with computer programs for a variety of applications such as search and retrieval, linguistic analysis, or visualizations. This modularity facilitates the various stagings within a given textual performance. For instance, the TEI-encoded documents of which In Transition is comprised include logical and ontological metadata that can describe both the physical and the semantic nature of the manuscript. Currently, the TEI schema is the most productive standard available for creating a scholarly edition of the Baroness's poetry because it is able to express the dynamic network of relationships that exist when multiple versions of a poem are performing at once. Created primarily for use with linguistic and literary documents, the standard has a robust schema for considering manuscript texts in multiple versions, making it suitable for the particular textual ontology on which a scholarly edition based on these kinds of texts depends. In particular, methods corresponding to the "Critical Apparatus" guidelines called "parallel segmentation" and "location-referenced," allow an editor to designate and thus visualize 
networks among linguistic codes (words, phrases, lines, paragraphs, etc.) and bibliographic codes (page images, page breaks, column breaks, and milestones) that correspond across various versions. In terms of In Transition, the TEI parallel segmentation encoding facilitates the reader's ability to compare the social text networks of a poem like "Xray" or "Sermon on Life's Beggar Truth" described above. In particular, In Transition uses the open platform application called the Versioning Machine (VM), ${ }^{6}$ which renders the TEI XML (shown in Figure 3) into a dynamic HTML page using XSLT, CSS, and JavaScript (shown in Figure 1 and Figure 2). Figure 1 and Figure 2 are examples from In Transition in which lines from various versions of "Xray" and "Sermon on Life's Beggar Truth" are being compared. With the VM styles, these comparisons can be enacted by readers dynamically in a browser window in two primary ways: (1) the scholar can open and rearrange version panels as needed and (2) the scholar chooses which networks to highlight by selecting lines of interest.

Figure 3: An excerpt of "Xray" in TEI P5 encoded XML, versions one through eight and the published 1927 text

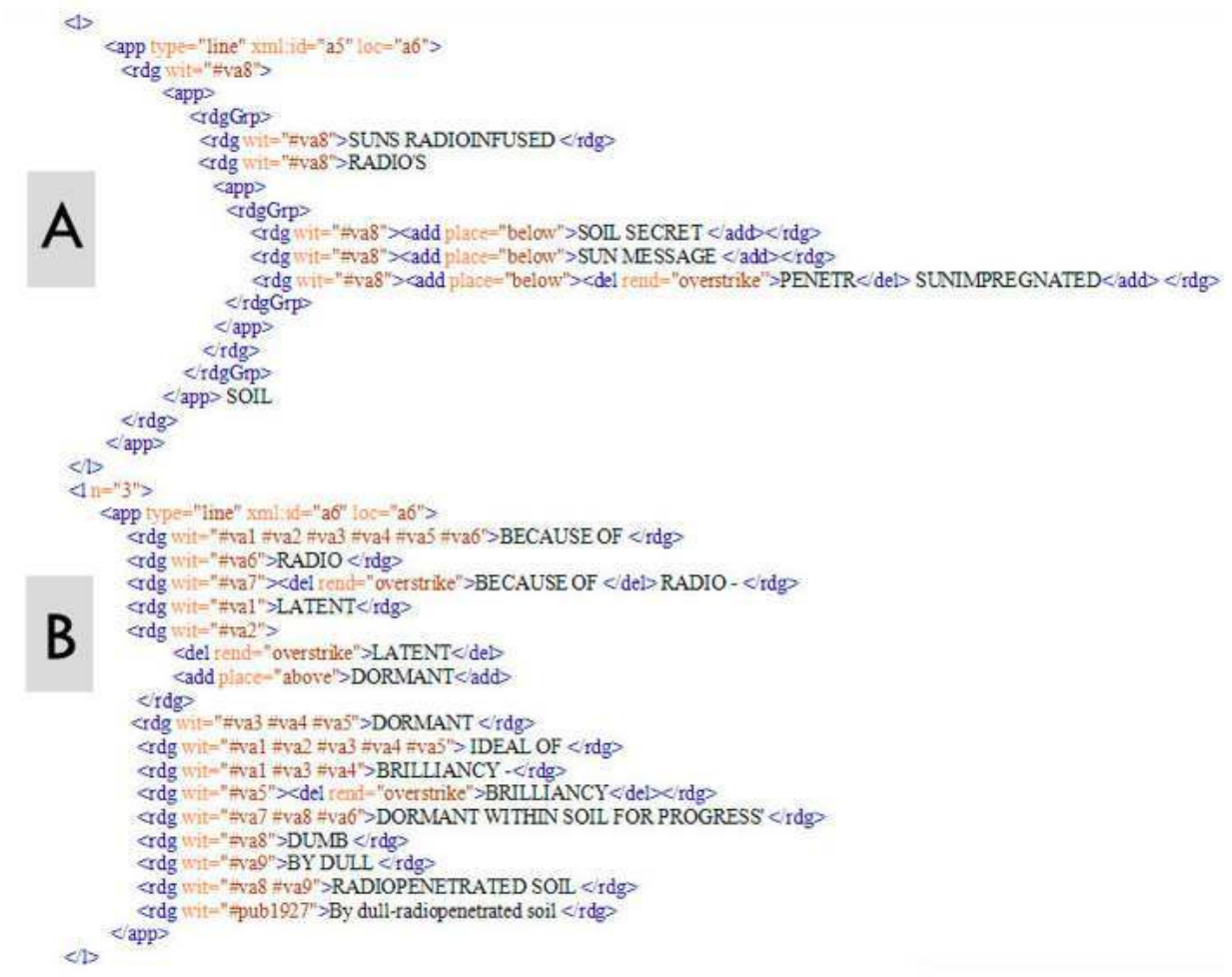

16 Determining which TEI elements present which social text networks is the work of knowledge representation. It is setting the stage for a textual performance. Critical, editorial choices that ensure textual modularity are involved in every aspect of the text's transformation from a transcript to a fully encoded TEI XML document to a text presented in an application such as the Versioning Machine. These choices include deciding how to sequence the versions, choosing the lines that correspond across versions, and assessing the HTML rendering of such choices. The underlying TEI XML of an edition such as In Transition (Figure 3) includes data within a structured logic that computer systems need to facilitate the scholar's ability to manage and manipulate various networks of relationships that comprise the bibliographic and linguistic codes of a text. For instance, in Figure 3, the logic represented by the "nested" structure indicates 
a particular relationship between the parent apparatus (<app>) element and the reading $(<\mathrm{rdg}>$ ) elements "nested" within it (the children) that allows the editor to indicate and compare corresponding parts of the text across versions. In this manner, the <rdg> elements that appear between the opening <app> and closing </app> elements indicate which of the nine versions or witnesses are associated with a particular aspect of the apparatus. The witnesses are indicated in the encoding by the numbers va1, va2, va3, etc. with the published version labeled as "pub1927." In this case, the apparatus with xml:id "a6" is being used to compare versions of the third line associated with each witness. In addition, the "loc" element (also "a6"), which links together readings from different apparatus elements, indicates that the <app> element with xml:id "a6" is associated with the <app> element with xml:id "a5." Consequently, the extra lines that appear in witness va8 above the third line (area "A" in Figure 3) are associated with this line of text across the versions. This "link" is visualized in Figure 3in which lines are highlighted according to the <app> element. In the interface, the reader can click on any line to automatically highlight associated words, phrases, and lines across readings based on two criteria: the presence of these readings within the same <app> element or the association of the same loc attribute on different <app> elements. The editor can use these structures to group or organize both unique versions and changes across versions and interface of In Transition allows the reader to see and construct different stories about the underlying networks of the text.

17 In considering the form of a digital scholarly edition, it is necessary to interrogate how the digital environment instantiates or stages the application of the underlying editorial philosophy. For instance, as a computable model, Willard McCarty calls encoded text "reductive and fixed" since it cannot detail "the massive amount and complexity of detail for a microscopic phenomenon across 12000 lines of text" (McCarty 2005, 58). An encoded text also cannot, according to Jerome McGann, capture the n-dimensional aspect of the "autopoetic" field of transactions, connections, and resonances. McGann notes that "[a]ll this phenomena exhibit quantum behavior. We distinguish a structure of relational segmentation in all texts, but in autopoetic forms we observe as well that the segments and their relations cannot be read as self-identical. They mutate into different symmetries and asymmetries" (McGann 2002, 298). On the other hand, in an essay titled "Electronic Textual Editing: When not to use the TEI," John Lavagnino discusses the advantages of using the TEI Guidelines for a scholarly edition. For a scholarly edition in which "the creation of new writing" such as scholarly apparatus is just as essential as the transcription of the original text, Lavagnino quite simply argues, "the TEI is applicable to your texts" (Lavagnino 2006, 334). The difference between these two perspectives is remarkable. The former is summarily reductive in considering the varied applications for encoding while the latter seems unduly expansive in theoretical terms. Certainly, as one reviewer of this article noted, there is a lot of information in the notes and introduction of In Transition that appear in natural language and are not essentially reliant on the "computable model" for "enactment." These notes represent static language about biographical and literary significance that describe a certain historical context. Yet, I am arguing that there are dialogic modes of knowledge representation enacted with this edition by both "natural" and "encoded" language and the premise underlying McCarty, McGann, and Lavagnino's claims speak to the reason for using the TEI to engage it: these critics are essentially saying that determining the standard or model for encoding a text 
depends on how the scholar defines the digital textual event in which it will be enacted (i.e., for what domain).

In theorizing how and why we use TEI encoding, it is useful to consider Sowa's observation that knowledge representation corresponds to "the application of logic and ontology to the task of constructing computable models for some domain" (Sowa, 2000, xii). McCarty's sense of the limitations of encoding are premised by his argument that the encoded text does not represent a productive computable model since the ontology created in an encoded text does not accurately represent the original object nor is it structured in such a manner to record what it is not able to represent. Essentially, McCarty's concern is to build a better system of representation based on what could be learned from a given model within that system. Likewise, McGann's perspective comes from his desire to represent the multidimensional "autopoietic field" of a textual event for observation and study. Lavagnino, on the other hand, defines the function of an encoded text in terms of editorial scholarship. As scholarly editors, he argues, "we are engaged in analyzing texts and creating new representations of them, not in creating indistinguishable replicas" (Lavagnino 2006, 338). Similarly, In Transition is a digital textual environment which is not intended to replicate history but is intended to elicit more questions than answers about social text networks through play, discovery, and inquiry. These performances are scripted by the editor-by my ability to mark and annotate aspects of the text that foreground certain networks and generate a particular narrative. These textual events, however, are also motivated by an underlying theory of textual performance which requires a real-time, live audience to "handle" the digital texts and images, to move them around and, by doing so, to set new autopoietic fields in motion.

\section{Knowledge Representation and Digital Scholarly Editions in Practice}

19 Applying the logic of the electronic edition (the form) and the ontology (the content) of these twelve networked texts to a computable model that represents textual performance (the domain) is not a simple task-but perhaps this difficulty is appropriate in this context. Richard Poirier writes that modernist "texts are mimetic in that they simulate simultaneously the reading/writing activity;" thus, "[t]he meaning resides in the performance of writing and reading, of reading in the act of writing" (Poirier 1992, 113). For this reason, he continues, modernist texts enact "a mode of experience, a way of reading, a way of being with great difficulty conscious of structures, techniques, codes and stylizations" (Poirier 1992, 114). For instance, the Baroness believed that punctuation (what she calls "interpunction") should be as varied and expressive as words. This sentiment is reflected in a note to Barnes in which she invents the "scorn mark" and the "joy mark":

... why does no scorn-mark mark of contempt-exist? I often miss it! see? that is one of thing's [sic] I will invent. . . to invent happiness-joy mark! Not only exclamation mark. Djuna-as I just see now-our interpunction-system is puny! One should be able to express almost as much in interpunction as words [...] in this new strange thing-to express absolute in it! As I did in sounds-like music! Wordnotes! (UMD 2.44) 
the Baroness acknowledges that her ontology includes the system of words and symbols from which she could draw and that these objects belong to a system or network of relationships that must reflect how we read but also how we write poetry. In Transition seeks to set this "performance of writing and reading" into play by engaging the reader in some of the same "difficult" textual conditions the Baroness encountered in creating her poetry, such as the play between elements of ontology (content) and logic (form) and the temporal nature of the writing experience in real-time.

Based on the theory of textual performance, In Transition illustrates through practice that versions are a matter of perspective and situation just as they are a matter of textual difference. For instance, two versions of a poem titled "He" and "Firstling" appear on the same manuscript page. Next to the versions, the Baroness writes a note to Djuna Barnes saying "These two poems are the same. I leave it to you if you will print them both?" (UMD 4.54) Other versions of the poems that appear in the extant manuscripts are German versions. On yet another version, the Baroness writes to Barnes about combining "Firstling" and "He" but this time "Firstling" is in German: "What is interesting about the 2 together," she writes,

is their vast difference of emotion-time knowledge-pain. That is why they should be printed together. For they are $1+2$ the same poem-person sentiment life stretch between one-divided-assembled-dissembled. The German one is youngnaïv [sic]-ingenous [sic] -the English one ripe-experienced bitter. The German one is deep woe of child-in whoms [sic] very violence thus naïve expressedlingers balm of recovery sensible.-The English one-as is superfluous to point outis grim sophisticated. (UMD 4.58-59)

The Baroness reiterates her idea that the poems are versions of the same poem though they have different titles, are written in different languages and written in different countries. The details the Baroness emphasizes, however, are differences made by time and experience. In fact, what she is describing is not only her experience in writing the poems at different times in her life, but what would eventually be the readers' experiences in reading this poem at a time later than they were written. Textual performance necessitates similar experiences with temporal uncertainties or instabilities. For instance, in "Prose Fiction and Modern Manuscripts: Limitations and Possibilities of Text Encoding for Electronic Editions," Edward Vanhoutte's main contention is that a genetic textual edition can only be partially accomplished by the TEI standard. He cites "time and overlapping hierarchies" as the most problematic aspects of his attempt to encode modern manuscript material since "the structural unit of a modern manuscript is not the paragraph, page, or chapter but the temporal unit of writing" (Vanhoutte 2006, 172). Clearly, he is not alone in contending that the TEI logic (the nesting elements) and its ontology (the aspects and behaviors of the text of which the elements are comprised) remain insufficient for representing modern textual events. ${ }^{7}$ On the other hand, perhaps it is not productive to assume that the TEI schema should be held culpable for the representation of every aspect of a textual performance. In "Psychoanalytic Reading and the Avant-texte," Jean Bellemin-Noël sites "chance" as the salient element within the textual event that mollifies the need to reproduce what could be called the text's originary temporality in the genetic edition. "Since the writing process is itself a production governed by uncertainty and chance," Bellemin-Noël writes, "we absolutely must substitute spatial metaphors for temporal images to avoid reintroducing the idea of teleology" (Bellemin-Noël 2004, 31). In other words, instead of attempting to reproduce temporality in the scholarly edition (an attempt that presupposes a teleological textual 
event), the goals of an edition with concerns about versions might be better served by engaging the element of uncertainty and chance that the temporal nature of textual events inevitably produce.

The facility to engage an element of chance, especially as it is engendered by space, is enhanced by a dynamic and manipulative interface to the textual event. Visualizations facilitated by a combination of text and image work well to produce a space that functions as a signifier for temporal uncertainty. For instance, in version three of "Xray," certain lines ("Suns [sic] radioinfused soil," "Radio's soil secret," "Radio's sun message," and "Radio's sunimpregnated soil") may be understood as alternative readings for the same point in a line of text because of their spatial arrangement (all radiating around the word "soil") on the manuscript page (see Figure 4). Or, since the text appears between the second and third line of text, the word cluster could be a kind of brainstorming cluster that may or may not have helped the writer develop the final phrase "Dumb radiopenetrated soil" that appears, for the first time in any version, on the line beneath the clustered constellation. Ultimately, uncertainty and chance are enacted by the spatial arrangement of the words on the page since it is impossible to ascertain which words were written first; consequently, our inability to decipher the exact chain of events is emphasized.

Finally, our access to this level of uncertainty is enacted by the combination of text and image that the VM facilitates. Within the TEI, the editor is able to express alternative readings for a given textual moment by using the reading-group element ( $<\mathrm{rdgGrp}>$ ) within a "parent" reading ( $<\mathrm{rdg}>$ ) element in order to group additional "children" readings (for an example, see <app> element xml:id "a5" in Figure 3, Area "A"). At the same time, TEI XML must be written in a linear form, first one reading, then another, which prescribes an order on text that is essentially unordered. ${ }^{8}$ For instance, in Figure 5, a $<$ rdgGrp> element is rendered by the presence of a dotted line under the phrase "Suns [sic] radioinfused". This line indicates that a mouseover will reveal alternative readings; yet, on the mouseover, the alternative readings are ordered, vertically, in the same order that the XML prescribes: first "Radios' soil secret" then "sun message" then "penetr sunimpregnated". This linear orientation is prescribed both by the XML and the resulting HTML (of which the VM interface is constructed), giving the impression that there is an order to the phrases that is not necessarily evident on the manuscript page. On the other hand, it is this discrepancy that lends a powerful element of uncertainty to the textual performance of "Xray" in the VM. That is, because of the encoding, a dotted line is rendered that indicates alternate readings for the phrase "Suns radioinfused soil" (see Figure 5). By mousing over the dotted line, the above-mentioned alternative readings appear in a "floating box" that indicates to the reader that the variants included in the box are alternative choices for this spot in the text. In addition, in this example, "soil secret" is also underlined with a dotted line indicating that alternative choices for this sub-reading are "sun message" and "sun impregnated." This is where the image enters into this performance. For instance, in Figure 5 and Figure 6, the encoded poem supports a logic of text according to linguistic codes that are associated across words and phrases. The image (shown in the bottom right corner of Figure 6) facilitates a logic of text that points to bibliographic codes associated with the material layout of the manuscript page. The dialogic that is played as these different textual messages are visualized through the encoded text and the manuscript images generates the element of temporal uncertainty that Bellemin-Noël mentions and that textual performance requires. In theory, "playing" 
the encoded text and image together opens a space for uncertainty, for conversation, and for situated, alternative readings that, in practice, become texts in performance.

Figure 4: Manuscript excerpt from "Xray" version three in the Versioning Machine

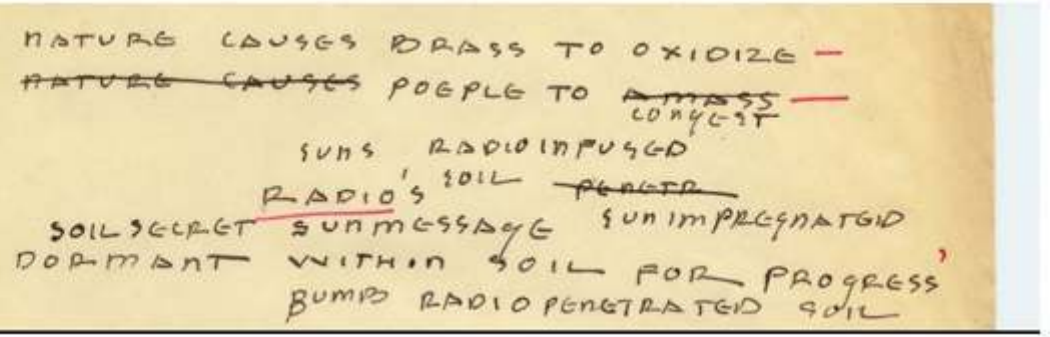

Figure 5: Excerpt from "Xray," three versions in the Versioning Machine

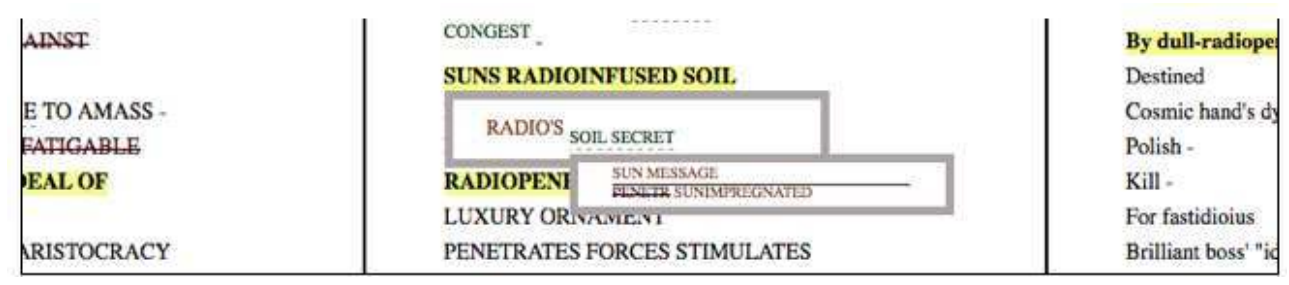

Figure 6: “Xray," three versions in the Versioning Machine

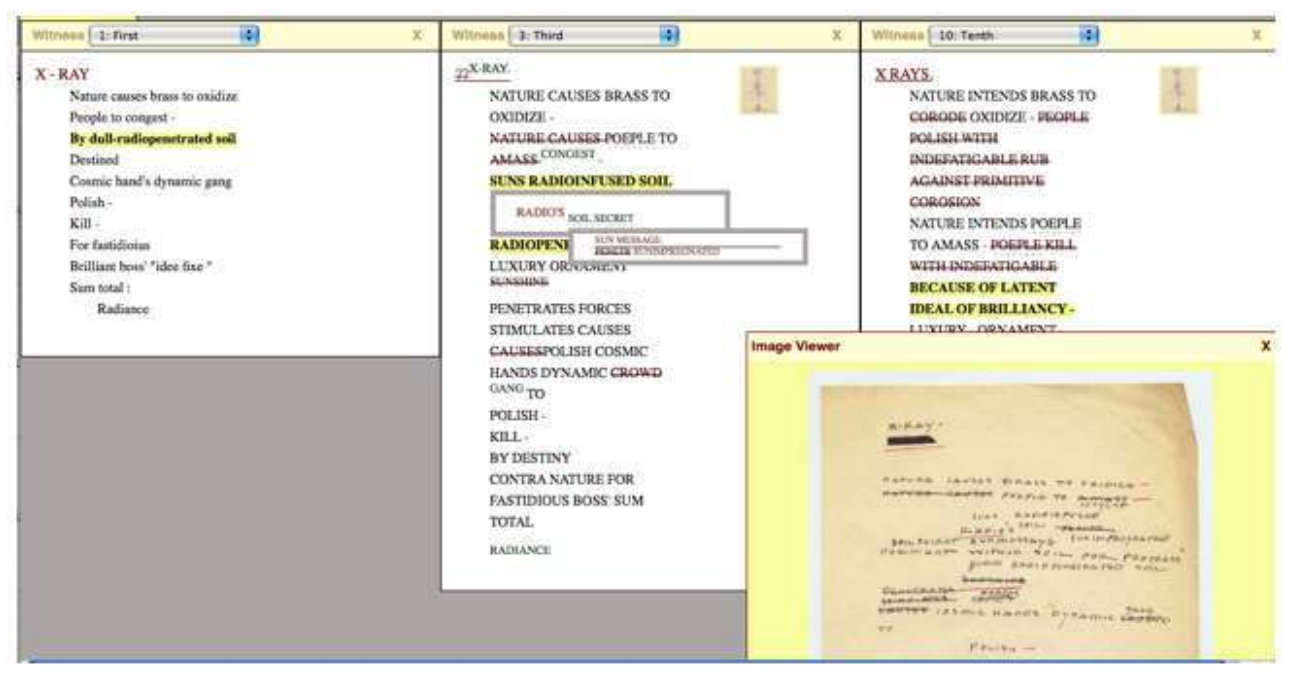

\section{Conclusion}

The knowledge represented and produced in creating and reading In Transition is provocative since it encourages critical inquiry concerning how a digital scholarly edition represents knowledge differently than a print edition; it raises questions about the role social text networks may have played in how the Baroness's poetry is and was presented and received; and it requires that we interrogate whether In Transition presents the Baroness in the trajectory of history or provides for a location in which we can read her work in the now, in an n-dimensional autopoetic field that is situated squarely in the present moment of the reader's open (browser) window. At best, with this work we imagine what is possible in creating a singularly digital text environment that requires 
the reader to ask, how does this environment work? How is it constructed? What new and traditional modes of textuality are at play and at risk here? The above discussion has sought to make transparent how the edition's ontology and logic are in dialog with the domain of textual performance. At best, the multiple versions of these twelve poems related through social text networks, the manifestation of these relationships in the TEI encoding, and the VM environment which allows users to set these relationships into play provides for a situated reading environment in which a particular instantiation of text is never the same from one moment to the next. The edition is enacting the element of realtime, live-body, evocative performance that informed how the Baroness and her contemporaries engaged in her poetry within social text networks of modernist magazines and the Dadaist art scene of the 1920s. At best, that work remains ongoing.

\section{BIBLIOGRAPHY}

Bellemin-Noël, Jean. 2004. "Psychoanalytic Reading and the Avant-texte." In Genetic Criticism: Texts and Avant-Textes, edited by Jed Deppman, Daniel Ferrer, and Michael Groden, 28-35. Philadelphia: University of Pennsylvania Press.

Bolter, J. David, and Richard A. Grusin. 1999. Remediation: Understanding New Media. Cambridge, Mass: MIT Press.

Bryant, John. 2002. The Fluid Text: A Theory of Revision and Editing for Book and Screen. Ann Arbor: University of Michigan Press.

Freytag-Loringhoven, Elsa. 2008. In Transition: Selected Poems by The Baroness Elsa von FreytagLoringhoven, edited by Tanya Clement. University of Maryland, College Park Libraries. http:// www.lib.umd.edu/digital/transition/.

1928. "Selections from the Letters of Elsa Baroness Von Freytag-Loringhoven," edited by Djuna Barnes. transition, 11 (February): 19-30.

. 1921. “Thee I Call 'Hamlet of Wedding Ring': Criticism of William Carlos William's [sic] ‘Kora in Hell' and Why ... (pt. 2).” Little Review 8 (Autumn): 108-111.

-_-. 1927. "Xray." transition, 7 (October): 135.

Gammel, Irene. 2002. Baroness Elsa: Gender, Dada, and Everyday Modernity: A Cultural Biography. Cambridge, Mass: MIT Press.

Golding, Alan. 2007. “The Dial, The Little Review, and the Dialogics of Modernism." In Little Magazines and Modernism: New Approaches, edited by Suzanne W Churchill and Adam McKible, 67-81. Aldershot, England: Ashgate Pub.

Hockey, Susan M. 2000. Electronic Texts in the Humanities: Principles and Practice. Oxford: Oxford University Press.

Huitfeldt, Claus. 2007. "Scholarly Text Processing and Future Markup Systems." Accessed October 10, 2010. http://computerphilologie.uni-muenchen.de/jg03/huitfeldt.html.

Latour, Bruno. 1993. We Have Never Been Modern. Cambridge, Mass: Harvard University Press. 
Lavagnino, John. 2006. “Electronic Textual Editing: When not to use TEI.” In Electronic Textual Editing, ed. Lou Burnard, Katherine O’Brien O'Keeffe, and John Unsworth, 334-338. New York: Modern Language Association of America.

McCarty, Willard. 2005. Humanities Computing. New York: Palgrave Macmillan.

McGann, Jerome. 2004. Marking Texts of Many Dimensions. In Companion to Digital Humanities (Blackwell Companions to Literature and Culture), edited by Ray Siemens, John Unsworth, and Susan Schreibman, 198-217. Hardcover. Blackwell Companions to Literature and Culture. Oxford: Blackwell Publishing Professional. Accessed October 10, 2010. http://www.digitalhumanities.org/ companion/.

-_-. 2002. "Visible and Invisible Books: Hermetic Images in N-Dimensional Space." In Literary and Linguistic Computing: Journal of the Association for Literary and Linguistic Computing 17 (April): 61-75.

-_-. 1991. The Textual Condition. Princeton, N.J: Princeton University Press.

Modern Language Association. "Guidelines for Editors of Scholarly Editions." 25 September 2007, accessed February 21, 201, http://www.mla.org/cse_guidelines.

Nelson, Cary. 1989. Repression and Recovery: Modern American Poetry and the Politics of Cultural Memory, 1910-1945. Madison, Wis: University of Wisconsin Press.

Papers of Elsa von Freytag-Loringhoven, Special Collections, University of Maryland Libraries. Digital edition available attached to the finding aid for the papers, accessed February 21, 2011, http://hdl.handle.net/1903.1/1501.

Poirier, Richard. 1992. "The Difficulties of Modernism and the Modernism of Difficulty." In Critical Essays on American Modernism, edited by Michael Hoffman and Patrick D. Murphy, 104-114. New York: G.K. Hall \& Company.

Renear, Allen, Elli Mylonas, and David Durand. 1996. "Refining our Notion of What Text Really Is: The Problem of Overlapping Hierarchies." In Research in Humanities Computing, edited by Nancy Ide and Susan Hockey. Oxford University Press, accessed February 21, 2011, http:// hdl.handle.net/2142/9407.

Richter, Hans. 1965. Dada: Art and Anti-Art. New York: McGraw-Hill.

Smith, Martha Nell. 1992. Rowing in Eden: Rereading Emily Dickinson. 1st ed. Austin: University of Texas Press.

Sowa, John F. 2000. Knowledge Representation: Logical, Philosophical, and Computational Foundations. Pacific Grove, CA: Brooks Cole Publishing Co.

Vanhoutte, Edward. 2006. "Prose Fiction \& Modern Manuscripts." In Electronic Textual Editing, edited by Lou Burnard, Katherine O’Brien O’Keeffe, and John Unsworth, 161-180. New York: Modern Language Association of America.

\section{NOTES}

1. More information about the Versioning Machine is at http://www.v-machine.org/. The iteration used for this project is based on VM version 4.0 with some modifications I implemented. These modifications are described at http://www.lib.umd.edu/digital/transition/vmchanges.jsp. 
2. This number represents a reel and frame number from the microfilm of the Papers of Elsa von Freytag-Loringhoven, Special Collections, University of Maryland Libraries. All subsequent references are noted as UMD.

3. Between 1927 and 1929, transition was edited by Eugene and Maria Jolas, Eliot Paul (until 1928), and Harry Crosby (until 1929).

4. Reception here is considered as part of a "triangular intertextuality" or only as one aspect of the "influences of biography, reception, and textual reproduction" (Smith 1992, 2).

5. This information is indicated in two letters between the Baroness and $\mathrm{M}$ rie Jolas at transition now housed at the University of Maryland Libraries. The letter from the Baroness asks the editors to include a dedication in "A Dozen Cocktails Please" to "Mary R.S." and to change a line in "Sermon on Life's Beggar Truth." While Jolas's return letter, dated October 12, 1927, does not mention "Sermon," she does note that they "are keeping for future use" the poems that the Baroness sent in with "Contradictory Speculations," namely "Ancestry," "Cosmic Arithmetic," "A Dozen Cocktails Please" and "Chill." "Chill" is not included in this edition because there are two poems by the Baroness titled "Chill," either of which could have been the one sent to transition (UMD 2.905).

6. More information about the Versioning Machine is at http://www.v-machine.org/. The iteration used for this project is based on VM version 4.0 with some modifications I implemented. These modifications are described at http://www.lib.umd.edu/digital/transition/vmchanges.jsp. 7. Of course, there are many discussions about the limitations of the TEI standard. For example, in his desire to create an electronic edition that expresses the time and space dimension a cache of multiple versions necessarily engages, Edward Vanhoutte discovers that speech elements serve his editorial principles since he considers his project to be a recording of the "author" having a conversation with the biographical writer (Vanhoutte 2006, 175-176). Other discussions include Renear et al., 1996; Hockey 2000, specifically pgs. 24-28; and Huitfeldt 2007.

8. As pointed out by one reviewer of this article, an extension can be added to the TEI Guidelines "to specify whether or not the order in the encoding of variants is significant or not; there's also the need for a customized interface that can signal this to the reader."

\section{ABSTRACTS}

In Transition: Selected Poems by the Baroness Elsa von Freytag-Loringhoven is a publicly available scholarly edition of twelve unpublished poems written by Freytag-Loringhoven between 1923 and 1927. This edition provides access to a textual performance of her creative work in a digital environment. It is encoded using the Text Encoding Initiative's (TEI) P5 Guidelines for critical apparatuses including parallel segmentation and location-referenced encoding. The encoded text is rendered into an interactive web interface using XSLT, CSS, and JavaScript available through the Versioning Machine (http://www.v-machine.org/). One aspect of textual performance theory I am exploring within In Transition concerns the social text network. The social text network these twelve texts always and already represent presupposes the notion of a constant circulation of networked social text systems. The network represented by In Transition is based primarily on issues of reception, materiality, and themes which engage and reflect the social nature of the text in the 1920s and now. This is to say two things: (1) that the concept of the network is not new with digital scholarly editions; and (2) that these networks in a digital edition foreground the situated 1920s history of these texts as well as the real-time, situated electronic reading 
environment. The argument of a digital edition like In Transition is formed as much by the underlying theory of text as it is by its content and the particular application or form it takes. This discussion employs the language of knowledge representation in computation (through terms like domain, ontology, and logic) in order to situate this scholarly edition within two existing frameworks: theories of knowledge representation in computation and theories of scholarly textual editing.

\section{INDEX}

Keywords: digital editions, interface development, knowledge representation, scholarly editing, text encoding, versioning

\section{AUTHOR}

\section{TANYA CLEMENT}

tclement@umd.edu

Associate Director, Digital Cultures and Creativity, University of Maryland, College Park Research Associate, Maryland Institute for Technology in the Humanities, University of Maryland, College Park

Tanya Clement is the Associate Director of Digital Cultures and Creativity, an undergraduate honors program at the University of Maryland, College Park. She has an English PhD from UMD and an MFA in fiction from the University of Virginia. She is also a Research Associate at the Maryland Institute for Technology in the Humanities (MITH). She has published chapters and articles on digital scholarly editing, text mining, visualizations, and literary modernism, is the Associate Editor of the Versioning Machine and the editor of In Transition: Selected Poems by the Baroness Elsa von Freytag-Loringhoven. 